\title{
EL PECADO ORIGINAL DE LAS HUMANIDADES
}

\author{
Aldo Mazzucchelli \\ Universidad ORT Uruguay / Brown University, Estados Unidos
}

\section{PÁRRAFOS CLAVE:}

“[...] el programa de las humanidades buscó en su origen histórico generar un espacio institucional para el despliegue del análisis y la interpretación de todos los problemas humanos por parte de un sujeto que se suponía libre [...] pero en la medida en que las humanidades en tanto camino de formación representan el espacio por excelencia en la universidad en donde el sujeto se pone a sí mismo como objeto de representación, se estudia, se convierte en un observador de segundo orden de su propio carácter de sujeto, a partir de allí, su plan de investigación no podrá nunca ser libre, sino que está siempre ya dictado por los contenidos verosímiles de lo imaginario, ajeno y colectivo. El "pecado original" del sujeto de las humanidades está en tal inevitable jugar su originalidad en una representación que necesariamente se vuelve de curso, ajena y pública. Al representarse, el sujeto se aliena de aquello que, en el ideal de la Bildung, consiste supuestamente su razón fundamental de ser, su carácter único y original. Es otra forma de ver la entrega de la verdad de sí a la lógica de la verdad de la ciencia”.

"Robert Zemsky hace una pregunta incómoda: 'Empresa y mercado han demostrado ser exitosos, ¿por qué razón no pueden operar las universidades más como empresas? ¿Por qué no pueden tener inteligencia de mercado?'Aunque la incapacidad de la academia para responder la pregunta de Zemsky no signifique que la discusión teórica o filosófica, es decir, la discusión dada en el campo de batalla y según las armas de las humanidades, sea ganada por las corporaciones, sí podría significar que la discusión en sí misma se termine lo cual es una derrota para las humanidades tout court. Es decir, que en los hechos el asunto quede en el campo de batalla y según las armas de las corporaciones, para las cuales semejante discusión teórica y epistemológica no es algo en lo que haya que entrar, sino simplemente algo que carece de sentido de antemano. Dicho de otro modo, algo sobre lo que hay que actuar". 


\section{ENTRE LA BILDUNG Y EL CINISMO}

Las humanidades dan raramente lugar a una discusión abierta en los últimos años. Pero la discusión sorda que de todos modos existe va resolviéndose por la vía de los hechos, con el cierre de algunos departamentos de lenguas romance y humanidades en algunas importantes universidades en el mundo, y con la no apertura de nuevos departamentos de ese tipo prácticamente en ninguna de las universidades fundadas en los últimos 30 años. Eso contrasta con el apoyo -y aun el crecimiento en algunos casos- que las humanidades igual experimentan en unos pocos espacios más tradicionales y más sólidos de la academia.

Las universidades de Stanford, Yale y Harvard son en los Estados Unidos tres de los espacios más notorios de apoyo a un nuevo relanzamiento de las humanidades, a menudo intentando desarrollar programas que las integren de un modo nuevo con las ciencias, como es el caso del programa BiblioTech o el Stanford Humanities Center (ambos en Stanford), el Whitney Humanities Center en Yale, o The Digital Humanities Initiative en Harvard. El hecho de que estos impulsos de apoyo a las humanidades brillen especialmente en universidades particularmente ricas y bien establecidas puede leerse en un sentido de excelencia: son las universidades más prestigiosas y más reconocidas las que están marcando el camino respecto a qué hacer con las humanidades. Pero también puede leerse al revés, viendo a las humanidades como un lujo que solo la elite y los más ricos pueden aun disfrutar.

El 6 de enero de 2008, un conocido académico literario norteamericano, el profesor Stanley Fish, publicaba un artículo en Opinionator, su habitual columna del New York Times, titulado "Will the Humanities Save Us?". A la-algo hiperbólica-pregunta, Fish responderá finalmente con un meditado "no", que argumenta al tiempo que repasa algunas posturas comunes respecto del punto en cuestión. La columna despertó una enormidad de respuestas tanto en el sentido cuantitativo como a veces cualitativo, por la virulencia de algunas de ellas. Puesto que se convirtió en un mojón en la discusión que nos ocupa, retomaré aquella columna y algunas de sus reverberaciones posteriores al fin de esta primera parte.

Pero antes de ir a Fish, plantear la cuestión sobre la que él se interroga, en sus líneas más definidas al menos, no tiene por qué ser largo ni difícil. Las humanidades tienen una historia que se remonta a la Antigüedad, pero como disciplinas académicas en su forma moderna existen institucionalmente desde el siglo XIX. Y el siglo XIX es un tiempo histórico de centralidad absoluta 
de lo escrito en el conjunto de la comunicación pública. En un tiempo en que la política y el poder se jugaban en la letra y en que cualquier proyecto de ciudadanía pasaba por el periódico y el libro, enseñar a leer y a escribir y dominar la cultura hermenéutica de la interpretación de textos se volvió una cuestión central al proyecto democrático moderno. También es relevante en ese momento la construcción de un pasado para las nuevas repúblicas europeas, y luego las americanas. Finalmente -como lo ha apuntado Hans Ulrich Gumbrecht- era importante que las nuevas repúblicas pudiesen dar a sus flamantes ciudadanos el espacio para un pacto en donde su ocio creativo y la promesa de un desarrollo individual libre pudiesen compensar las penurias de orden social y vida convencional generalizados, que por primera vez se les exigía. Tal contrato no escrito fue en parte llenado con el desarrollo institucional y "al alcance de todos" de las artes y las humanidades. Las universidades desarrollaron sus departamentos de humanidades para enfrentar, entre otras menores, dos tareas mayores: 1. Investigar y editar los textos que proveyesen a las nuevas nacionalidades de una tradición venerable (a través de la vieja filología en los nuevos Departamentos de Letras, y a través de la historia), y 2. Formar ciudadanos capaces de manejar el poder de lo escrito y el poder a través de lo escrito, y de elaborar una teoría contemporánea de los textos escritos (respectivamente a través de la adaptación de la vieja retórica en los nuevos departamentos de Letras, y a través de la filosofía). $\mathrm{Al}$ tiempo que en materia de Wissenschaft esta era la tarea, en su dimensión educativa, las humanidades fueron el espacio privilegiado para la Bildung, es decir, para permitir y orientar el desarrollo de las potencialidades de cada individuo/ciudadano de las repúblicas modernas de modo autónomo, libre y, sobre todo, único. El sujeto debía tener la posibilidad de convertirse en un sí mismo original, a través del desarrollo armónico de -idealmente todas-sus facultades y sus potenciales.

Ahora bien, este impulso histórico vino acompañado de un movimiento fatal de las humanidades, parte esencial de su "pecado original", hacia la creación de formas epistemológicas científicas. Si bien, cómo se verá luego, el asunto generó una amplia polémica ya en Alemania durante los albores de las modernas humanidades, la verdad es que las aproximaciones literarias e históricas de cuño positivista y científico empezaron a dominar la historia, las letras y luego aun la filosofía en todas partes, por la vía de dominar sus teorías. Materialismo, positivismo, objetivismo campearon por todos lados hasta convertirse en un elemento que se da por sentado en demasiados casos. Esa "cientifización” en el proceso de legitimación de las 
humanidades es probablemente una de las semillas de su actual decadencia. No hace falta casi ni decir, para terminar este rápido repaso inicial, que en la medida en que lo escrito y los "textos" en su concepción moderna -analítica, modular, acumulativa y extensa- desaparecen rápidamente del centro de la comunicación social y política, va desapareciendo también uno de los fundamentos iniciales de las humanidades modernas. Junto a todo ello, es el individuo - modelo moderno, siglo XVIII y XIX- el que se eclipsa. La discusión sobre las humanidades pues se subsume ahora, en mi opinión, en una discusión más amplia acerca del rol de lo escrito, lo oral y de la ecología mediática en la sociedad contemporánea y futura, y ligado naturalmente a ello, una reformulación del problema y la fenomenología del sujeto y lo subjetivo en la sociedad virtual contemporánea.

Pero si esa es una posible síntesis de la historia conceptual del problema, es preciso recuperar algunas de las líneas tradicionales de discusión, que aún no tenían en el centro estos problemas contemporáneos del lugar mismo de la letra en la sociedad y la comunicación. Vayamos entonces ahora a la discusión tal como la veía Fish en 2008, pues ella revela algo de esa otra forma, más tradicional e interna, de vertebrar los argumentos clásicos a favor y en contra de la existencia de los departamentos de humanidades en la universidad. Forma que depende sobre todo de la cuestión de la Bildung. Fish comenzaba relevando algunas de las explicaciones ofrecidas al hecho de la disminución de la asistencia financiera a las humanidades. Candidatas a responsables por tal falta de apoyo serían desde "las políticas de izquierda [seguidas unánimemente por esos departamentos en las universidades norteamericanas] que corren a la gente", como alegaba Sean Pidgeon, hasta "la ausencia de una cultura que privilegie el aprendizaje para mejorarse a sí mismo como ser humano", que sugería Kedar Kulkarni. Otro de los opinadores citados, de apellido Matthew, después de comentar que para él no dar plata a los departamentos de humanidades era exactamente la actitud correcta, agrega una frase rotunda: "El día que un poeta cree una vacuna o un bien tangible que pueda ser producido por una compañía de las que entran entre las primeras 500 de la revista Fortune, cambiaré de idea". Fish observa que el problema de la falta de fondos está pues ligado, como lo sugiere la última frase, con la cuestión de la legitimidad o justificación de la existencia de tales departamentos, una justificación que en el mundo contemporáneo viene casi siempre de la mano con la noción de utilidad. Y aventura Fish que varias de las justificaciones clásicas ya no funcionan, pues las humanidades ni producen egresados que sean particularmente útiles al mercado laboral, ni tampoco la cultura media 
de un egresado de humanidades -según Fish, poder espolvorear algo sobre Shakespeare o sobre Michel Foucault en una conversación cualquiera- es un capital simbólico atractivo en las conversaciones de hogaño. Más bien al revés, tiende a irritar al interlocutor, observa el profesor americano.

Ahora bien -y he aquí la herencia de la concepción de Bildung-, en los viejos tiempos, una justificación de cualquier índole no era necesaria pues todo el mundo que contaba asumía que un "college" era "sobre todo el lugar donde se entrenaba el carácter, donde se nutrían los hábitos morales e intelectuales que juntos forman la base para vivir la mejor vida posible" y se seguía de ello, dice Fish, que esos hábitos se adquirirían en cierta vecindad o aun intimidad con las grandes obras de la literatura, la filosofía y la historia. Apurada no obstante una justificación más articulada para la enseñanza de las humanidades, una postura clásica respondería que "los ejemplos de acción y pensamiento retratados en las obras duraderas de la literatura, la filosofía y la historia pueden crear en los lectores el deseo de emularlos". Estas ideas "suenan muy bien", dice con sorna Fish. Pero, agrega, "no hay evidencia que las apoye, y una cantidad de evidencia en contra". "Si esto fuera cierto, la gente más honesta, paciente, generosa y de buen corazón sobre la tierra serían los miembros de los departamentos de letras y filosofía, que pasan sus días en compañía de los grandes libros", y tal cosa evidentemente no es cierta. Ni los profesores - ni menos, entonces, los estudiantes-de literatura y filosofía aprenden cómo ser buenos y sabios; lo que aprenden, observa Fish, es "a analizar efectos literarios y a distinguir entre distintos relatos acerca de los cimientos del conocer".

Las conclusiones de Fish son breves y rotundas. Mientras que lo anterior le parece a Fish que es como debe ser, y que no se le debe pedir a las humanidades que enseñen moral o sabiduría, a la pregunta de "¿para qué sirven las humanidades?", Fish responde: para nada. Y agrega "Y esta es una respuesta que honra a su objeto. Pues la justificación de una actividad cualquiera, después de todo, confiere un valor a tal actividad desde una perspectiva ajena a la actividad misma. Y una actividad que se niega a ser justificada es una actividad que rechaza verse a sí misma como instrumental a un bien mayor que ella. Las humanidades tienen su bien en sí mismas".

Esta visión, que tiene sin duda ecos de Kant y que aparentemente devuelve el proyecto de las humanidades a sus raíces modernas, "suena muy bien", yo diría, salvo que el mundo contemporáneo no parece haberse enterado de ello y persiste en su intención de entender ese "bien en sí" de las humanidades en relación con otras esferas y otras prácticas como ética aplicada a la biología, o 
como insumo para discusiones políticas que incidirán en decisiones jurídicas muy concretas, o como un entrenamiento de los sentidos y la inteligencia para moverse en una vida cultural cada vez más intrincada.

La cuestión tiene pues que quedar abierta. Hay quienes han objetado a Fish que si ese -el goce desinteresado de objetos intelectuales interesantes o bellos- es todo el bien que las humanidades representan, realmente no habría un motivo para cultivarlas o enseñarlas salvo el placer que dan a sus practicantes, cosa con la que Fish seguro está de acuerdo, pero que es difícil que convenza a los encargados financieros de las instituciones de enseñanza en el mundo real.

En realidad, apunto, lo que Fish olvida en una postura que a fin de cuentas es cínica, es que si las humanidades no pueden ya casi encontrar significación en una formación del carácter y la personalidad que estuvo claramente en la base del proyecto original, eso es en buena medida porque con la caída -exclusivamente en Occidente- de cualquier noción trascendente de verdad, cayó la única base que podría haber permitido que una discusión cualquier conduzca, en último término, a una convicción firme y transmisible. En parole povere: $\sin$ metafísica - o sin fe genuina- no puede haber humanidades. Pues el proyecto original de las humanidades nunca fue enseñar "a analizar efectos literarios" por sí, sino como una parte del quehacer universitario cuyo centro estaba en la Wissenschaft -investigación y la práctica de enseñanza- de materias cuyos contenidos, a comienzos del diecinueve, aún se creía orientados y en relación con una verdad mayor y más estable que la mera opinión de los sujetos. Que el desarrollo del objetivismo y positivismo primero, y del relativismo y perspectivismo posteriormente, expliquen que hoy nadie o casi nadie crea que las humanidades tienen que ver con el desarrollo de algunos "valores humanos", no hay duda. Pero la postura que adopta Fish toma ese dato como un hecho meteorológico que ni tiene causas ni podrá tener cambio alguno, y pretende justificarlo con una lectura blanda de la tercera crítica kantiana. Para entender cómo es que se llega a que una postura como la de Fish suene natural y casi obvia, hay que repasar por un momento la historia de lo que la mayoría da por sentado hoy al discutir sobre humanidades. Esto es, cierta postura clásica del utilitarismo cuando mira a la educación. De eso se ocupa la segunda parte de esta revisión. 


\section{LAS HUMANIDADES Y LAS CORPORACIONES}

"He escrito un libro que sospecho no será de agradable lectura para los profesores y los estudiantes de doctorado, puesto que no sólo he indicado sino también fundamentado cuáles son las fuerzas de mercado y las prácticas institucionales profundamente entrelazadas que, eventualmente, nos destruirán. Pinto lo que podría llamarse un cuadro inequívocamente sombrío acerca de lo que depara el futuro para los profesores de humanidades, y no ofrezco nada en el sentido de soluciones estimulantes a los problemas que describo. Pienso que los profesores de humanidades han perdido ya la capacidad de rescatarse a sí mismos".

Lo que antecede es una cita textual extraída del prefacio de The Last Professor. The Twilight of the Humanities in the Corporate University, por Frank Donohue (la edición Kindle está disponible por doce dólares). Como se entiende enseguida al leer la cita, Donohue no cree que haya ninguna crisis, es decir, no cree que se trate de una coyuntura que plantea desafíos nuevos que pueden ser resueltos. Lo que él cree es que simplemente el proyecto histórico de enseñar las disciplinas humanísticas en una relación de estudiante-profesor ha muerto, y que no hay nada serio que hacer al respecto. Fin de la historia.

Los argumentos de Donohue son persuasivos, y resumen bien lo que se viene debatiendo en torno al posible o imposible futuro de las humanidades. Como se ha visto recién, Stanley Fish aventuraba que, ante el creciente desafío planteado a las humanidades por un contexto de mercado cada vez más radicalmente centrado en la utilidad y los resultados cuantificables (y beneficiosos financieramente), la única respuesta era reivindicar la autonomía y la belleza del desinterés: el saber no puede arbitrarse o juzgarse a partir del mundo de la utilidad, pues el saber tiene su virtud en sí mismo y no se lo busca para algo exterior a sí mismo. Los administradores financieros de las universidades del mundo real -salvo unas pocas con muy anchas espaldas en términos tanto de tradición académica como de dinero, como Harvard, Stanford o Yale- no parecen haber sido mayormente persuadidos por tal argumento. Es precisamente lo que argumenta Donohue a lo largo de las densas ciento ochenta páginas de su libro. El problema que la "universidad de las corporaciones", como la llama Donohue, ha planteado a las humanidades tiene más de un siglo de existencia. Los ataques a las humanidades vienen de la visión que dice que cosas como la filosofía o la literatura son pérdidas de tiempo y carecen de utilidad en el mundo de los negocios. Andrew Carnegie, el magnate de la industria, dijo una vez que la educación tradicional en un 
college americano dejaba a los graduados "bien adaptados para la vida en otro planeta" y que el tiempo gastado en Shakespeare y Homero era tiempo perdido, mientras que Richard Teller Crane, fundador de una compañía con base en Chicago que es hoy parte de las 500 de Standard \& Poor, afirmó en 1909 que "nadie que tenga gusto por la literatura tiene derecho a ser feliz", puesto que "los únicos hombres con derecho a la felicidad en este mundo son los que resultan útiles para algo". Observa Donoghue que ya defensores de la educación como Thorstein Veblen o Upton Sinclair arguyeron que tal aplicación de estándares comerciales era cruda e injusta. Sin embargo, los valores de las corporaciones han logrado estructurar el campo mismo de la universidad en el que todavía sobreviven los profesores y los departamentos de humanidades. Se trata de una situación en la que las profesiones humanísticas no tienen siquiera autonomía financiera: dependen, para poder desarrollar su trabajo, de las dádivas entregadas por sus propios enemigos epistemológicos.

Las citas de Carnegie o Teller ¿son atrocidades y extremismos o son meramente la forma más expuesta y directa de decir exactamente lo mismo que piensa hoy la mayor parte de administradores y dirigentes de las universidades alrededor del mundo? Para contestar la incómoda pregunta basta mirar cuál es el espacio y los recursos dados a las humanidades en la universidad contemporánea. Enseguida se comprobará -siguiendo con el caso de Estados Unidos, que por muchas razones sirve de fundamental punto de referenciaque a partir especialmente de la crisis económica de 2008 ha abundado la información referida a cierres o severos cortes afectando a los departamentos de humanidades, y que el argumento subyacente es crudamente económico: si tengo que recortar, recorto primero lo más superfluo.

Esta relación entre la ideología de las corporaciones y la educación en humanidades tiene también una historia, y Donoghue propone una lectura de ella que hila más fino al definir etapas y contenidos. Durante la etapa inicial de expansión del capitalismo monopólico y no regulado, las corporaciones meramente vieron a las humanidades como inútiles. En cambio, "los industrialistas maduros de los años 40, 50 y tempranos 60 en cierto modo apoyaron las humanidades como defensa contra lo que se veía como una desalmada Unión Soviética. [...] La América de las corporaciones vio nuestro mensaje como útil durante esos años, y el boom que vivieron las humanidades en la segunda posguerra se debe en parte a la buena voluntad del gobierno y las corporaciones, por vago y mal examinado que haya sido el esfuerzo hecho en apoyarnos. Luego, desde el comienzo de la era Reagan, las corporaciones han visto a la educación superior como un fastidioso problema laboral. El 
desmontado del profesorado norteamericano es parte de la casualización del trabajo en general, un fenómeno que comenzó en 1980 y se ha acelerado desde entonces".

Lo paradójico es que debido al aumento del número de estudiantes en la educación superior, las universidades han seguido necesitando y contratando profesores, para desmayo de quienes desearían que las universidades funcionasen estrictamente como una empresa, optimizando eficacia, eficiencia y ganancias. Ese aumento de contrataciones sin embargo ha ocurrido al tiempo que va ocurriendo un proceso de creciente "casualización" del contrato laboral: cada vez son menos los profesores con contratos estables, bien remunerados y con buen equilibrio entre tiempo para la investigación y tiempo de docencia. En cambio, aumentan geométricamente los ayudantes, asistentes, profesores en relaciones laborales inestables, peor pagos y con mucho menor tiempo para la investigación. El taylorismo (eficiencia, productividad y utilidad) sigue estando en el trasfondo de las críticas contemporáneas a las humanidades, cuyo contenido no ha evolucionado demasiado desde los tiempos a su modo heroicos de Crane y Carnegie. Y la pregunta de Robert Zemsky citada por Donoghue es bastante incómoda aún hoy. Es la siguiente: "Empresa y mercado han demostrado ser exitosos, ¿por qué razón no pueden operar las universidades más como empresas? ¿Por qué no pueden tener inteligencia de mercado?". Donoghue teme que las humanidades sean completamente incapaces de responder a esta pregunta.

Ahora bien, dejemos a Donoghue para observar un punto clave que hasta ahora ha quedado en el trasfondo de esta secuencia. Aunque la incapacidad de la academia para responder la pregunta de Zemsky no signifique que la discusión teórica o filosófica, es decir, la discusión dada en el campo de batalla y según las armas de las humanidades, sea ganada por las corporaciones, sí podría significar que la discusión en sí misma se termine, lo cual es una derrota para las humanidades tout court. Es decir, que en los hechos el asunto quede en el campo de batalla y según las armas de las corporaciones, para las cuales semejante discusión teórica y epistemológica no es algo en lo que haya que entrar, sino simplemente algo que carece de sentido de antemano. Dicho de otro modo, algo sobre lo que hay que actuar.

Esto último plantea un nuevo aspecto de la discusión, que se considerará en seguida. Me refiero a la medida en la cual la legitimación de la discusión misma acerca del futuro de las humanidades está en manos de la tradición humanística, o fuera de ella. Lo cual tiene que ver con una discusión más fundante, que atañe al tipo de teorías con el que las humanidades mismas 
han justificado su existencia y su razón de ser en los dos últimos siglos. Esa discusión teórica ha mostrado cómo el caballo de Troya (para usar una imagen de tradición humanística) de la utilidad y la objetivación del sujeto se ha metido dentro mismo de los fundamentos del campo, esencialmente enemigo, de las humanidades. Los resultados están a la vista. Las humanidades parecen haber preparado, debido precisamente a su nobleza y su compromiso con el examen crítico de todos los aspectos de cualquier cuestión, su propia destrucción.

\section{UN SUJETO SIN CONTROL DE SÍ MISMO}

En las primeras dos partes de esta secuencia se hacía referencia a algunas discusiones más o menos contemporáneas acerca del futuro de las humanidades, circunscriptas ellas a la academia norteamericana, que no es igual ni subsumible en otras como la francesa, alemana, o aun latinoamericana. Se terminaba observando que una cuestión relevante es quién sienta las formas de legitimación del debate acerca de si tiene sentido o no continuar con la institución de las humanidades dentro de la enseñanza superior. En otras palabras, si unos supuestos utilitaristas son los que dan el marco para debatir, es muy poco probable que las humanidades logren superar la discusión, mientras que si el debate se acepta y se da según supuestos de la propia tradición humanística, el resultado sería seguramente el inverso. "¿Quién manda en el debate?", pues, es cosa previa. Y es cosa ardua, pues de acuerdo a la organización institucional de los discursos, una cantidad abrumadora de veces quien manda en el debate es quien manda en el dinero.

La cuestión, apenas así planteada, revela que lo que se ha venido discutiendo no es en realidad si las humanidades si o no, y cómo, sino simplemente si en el próximo presupuesto de, digamos, la Universidad del Estado de Nueva York, habrá o no dinero para el Departamento de Lenguas Eslavas, y cuánto. Es decir, de lo que Stanley Fish y otros se han venido haciendo eco es de los ecos de un debate presupuestario cerrado en sí mismo y que se procesa caso a caso, no se discute sobre la estrategia, pero se resuelve sobre la táctica. Y pese a los distintos esfuerzos de abrir tal debate al público, darle alguna dimensión política, y quizá por esa vía intentar hacerlo más interesante, se hace difícil conectarlo con debates epistemológicos más de fondo.

Acerquémonos a estos últimos. Algunos ingredientes nuevos, contemporáneos, que creo debieran formar parte de esos debates más de fondo son los siguientes (los enumero sin esperanza de ordenarlos, y mucho menos de ser exhaustivo): 
lugar de lo escrito (la tradición de lo escrito como área de conocimiento y como medium del conocer) en la sociedad y en la ecología mediática; rol de la representación en la historia y peripecia moderna del sujeto; relación de las disciplinas humanísticas con los campos científicos rectores de la investigación "moderna" (s. XIX) aplicada siguiendo al primer Foucault en "Les mots et les choses": vida, economía y lenguaje; relación tecnologíaconciencia; perfil educativo ideal (o virtual) para un posible ciudadano de las décadas en que estamos instalados y las que vienen. Finalmente, lo que he insinuado más arriba en este texto: el carácter de invaginación o nulo de la discusión epistemológica. Dicho de otro modo: las humanidades están pasando a carecer de autonomía epistemológica. La declaran, apoyándose en su historia, pero el desarrollo del saber, el valor y la legitimidad están escapando irremisiblemente de los ámbitos sociales y discursivos que las humanidades controlan.

El alcance de cada una de estas dimensiones es conceptualmente apreciable, y en relación con ellas se podría discutir la cuestión de si la institución de las humanidades tiene todavía algún lugar bajo el sol de la universidad, y cuál y cómo debiera éste ser. Por ejemplo, en relación con la primera cuestión es evidente que la escritura ni ha desaparecido ni es menos practicada ahora que antes. Pero es igualmente evidente que su rol dentro del conjunto de los medios ha cambiado dramáticamente con respecto no solo a hace un siglo y medio (cuando se diseñó la institución de las humanidades) sino a hace una década. La gente sigue escribiendo e integrando su escribir a muchas de las nuevas plataformas tecnológicas que van apareciendo. Pero la gente no sigue escribiendo y leyendo, mayoritariamente, el mismo tipo de textos que antes, ni estos juegan el mismo rol masivo que antes jugaban (lo escrito ya no es vehículo principal, por ejemplo, de la discusión política general), ni la relación lector/escribiente/texto es ya como era. La referencialidad del opinar, conocer y elegir ha migrado, de una discusión con referencia cultural en la "tradición de Occidente" a una miríada de discusiones tácticas sin referencial cultural canónica posible. El logos no se abre solo ni primordialmente en lo escrito, y el rol de lo escrito en relación con el conocer y el ser ciudadano informado y decisor palidece. Eso afecta al núcleo de todo pensar en la necesidad y forma de una disciplina de tipo humanístico. ¿Para qué tipo de lectura y escritura formar al público universitario? ¿Para dar discusiones inscritas en qué tradición, en qué marco referencial? ¿Cómo es la forma de pensar y relacionarse con el mundo de alguien formado en la lectura de textos, a secas, versus la de alguien predominantemente oral o formado únicamente para el uso de textos breves? 
Una segunda cuestión ha sido definida mejor que en cualquier otro sitio que conozca en un justamente famoso ensayo de Martin Heidegger, traducido al castellano como "La era de la imagen del mundo". El filósofo argumenta allí que "lo decisivo" de la modernidad es que en ella "la esencia del hombre se transforma desde el momento en que el hombre se convierte en sujeto". El problema con ello es que, a la vez que el sujeto se configura finalmente como en estado de "madurez" y "responsable" de sus propias acciones (según el famoso y breve decir de Kant en "Qué es la Ilustración”), se hace imposible que cualquier cosa que pueda representarse como "su" posición, voluntad o interés escape al juego de lo que ya está previamente a disposición, "objetivamente", como representable. El sujeto existe solo en tanto un objeto más entre otros, presa de las mismas dinámicas y presiones que el resto de lo objetivo, y solo como un objeto más puede representarse a sí mismo. Su investigación (humanística o científica), es decir su voluntad de dirigirse en algún sentido, está desde ya objetivada en posibilidades que no le pertenecen.

La representación del hombre (y de "lo humano" y de todos sus posibles contenidos) se vuelve así un hecho externo y saca para siempre al sujeto de cualquier ilusión de individualidad "pura". El proceso de objetificación del mundo culmina apropiándose también, aun cuando sea de una forma tensa y resistida, de todo posible sí mismo. El "proyecto romántico" de las humanidades, como lo llama al pasar el mismo Heidegger, solo puede resistir un tiempo en ese contexto, pero está condenado y deja de tener un lugar en la esfera de las líneas posibles de investigación, las que por otra parte están completamente institucionalizadas, pues es imposible obtener una legitimidad "individual" y no institucional. La pregunta del comienzo acerca de quién determina la legitimidad de la discusión por el "futuro de las humanidades" queda así contestada.

Si esta visión es correcta (y la intensa capacidad de los textos de Heidegger para anticipar y formular la era de la técnica y la tecnología parecen así sugerirlo), el programa de las humanidades, que buscó en su origen histórico generar un espacio institucional para el despliegue del análisis y la interpretación de todos los problemas humanos por parte de un sujeto que se suponía libre, ya sea desde una perspectiva hermenéutica, teórico formal o historicista, se revela como una utopía institucional que tiene que haber empezado a hacer ruido desde prácticamente su creación. Y efectivamente, las humanidades comenzaron a hacer ruido en el momento mismo en que comenzaron. Pues en la medida en que las humanidades en tanto camino de formación representan el espacio por excelencia en la universidad en donde 
el sujeto se pone a sí mismo como objeto de representación, se estudia, se convierte en un observador de segundo orden de su propio carácter de sujeto. A partir de allí, su plan de investigación no podrá nunca ser libre, sino que está siempre-ya dictado por los contenidos verosímiles de lo imaginario, ajeno y colectivo. El "pecado original" del sujeto de las humanidades está en tal inevitable jugar su originalidad en una representación que necesariamente se vuelve de curso, ajena y pública. Al representarse, el sujeto se aliena de aquello que, en el ideal de la Bildung, consiste supuestamente en su razón fundamental de ser, en su carácter único y original. Es otra forma de ver la entrega de la verdad de sí a la lógica de la verdad de la ciencia. Todo esto está claramente prefigurado en el modo cómo se negoció la organización institucional de las humanidades desde su origen histórico a comienzos del siglo diecinueve, materia del próximo apartado.

\section{EXCURSO HISTÓRICO: BILDUNG, EDUCACIÓN, LIBERTAD INDIVIDUAL}

En el otoño de 1810 se impartían los primeros cursos en la Universidad de Berlín. Ese momento marca lo que en general se considera el arranque de la universidad moderna. Filosofía, historia, filología, matemáticas, y antropología son las disciplinas que se dictan inicialmente allí. Una sintética mirada a dos aspectos del proceso por el cual se llega a la creación de esa universidad, modelo para el resto en el mundo transatlántico, ayuda a comprender la raíz histórica del problema de primacía al que se viene aludiendo, directamente hoy desembocado en el debate sobre el futuro de las humanidades.

Claude Piché ha resumido esta discusión en un artículo ("Fichte, Schleiermacher y W. von Humboldt, sobre la creación de la Universidad de Berlín") que seguiré en general al revisitar dos de los puntos que resultan claves desde aquella discusión. El primero es la cuestión genética de preminencia o no de la filosofía dentro de la universidad -resuelta al cabo en creciente y rápida autonomización de las ciencias empíricas. Este punto es clave porque, como lo he adelantado, si no es en el campo de batalla de la filosofía sino en el de la empresa donde se discute el futuro de las humanidades, no habrá ya siquiera una discusión al respecto -cosa que está claramente ocurriendo. La segunda, y aun más importante acaso, es que dependiendo de la concepción de sujeto implícita en la comprensión de la formación personal o Bildung -es decir, dependiendo de si se trata de un sujeto estrictamente jurídico o de otro más integral- resultará uno u otro énfasis en los principios de la cuestión educativa general. 
Sobre el primero de los puntos, la misión de la universidad de Wilhelm von Humboldt y Friedrich Schleiermacher, recuerda Piché, "gravita esencialmente en torno de la Wissenschaft" (es decir, a las ciencias que implican investigación sistemática y enseñanza, por oposición a la formación técnica y profesional). En esta concepción, todas las disciplinas, incluidas las ciencias empíricas, atañen en alguna medida a la filosofía -en la medida, precisamente, en que es la filosofía la que tiene la capacidad de discutir los principios epistemológicos y éticos de la investigación en cada una de ellas. De ahí no se deduce naturalmente, sin embargo, que la filosofía deba, en la práctica, tener alguna jerarquía superior dentro de la organización universitaria. Tal preminencia no solo epistémica sino incluso en términos de poder universitario, de la filosofía, fue defendida desde el comienzo por Johann G. Fichte, uno de los tres actores más importantes en esta discusión originaria de la universidad moderna. Tanto él como Schleiermacher presentaron proyectos de organización para la nueva universidad, y tocó a Humboldt la decisión final sobre el tema. La concepción de Fichte, más vertical y con énfasis en la idea de un desarrollo de los estudiantes hacia la perfección de una verdad única, final y uniformizadora, así como más orientada a la especialización, resultó en general derrotada en aquella polémica inicial, pues Humboldt decidió apoyarse en una concepción más liberal que en general compartía con Schleiermacher. Sin embargo, Schleiermacher justo en este punto convergía con la concepción de Fichte. En su Gelegentliche Gedanken über Universitäten in deutschem Sinn" ("Pensamientos ocasionales acerca de la universidad en sentido alemán", de 1808), Schleiermacher establece que la "filosofía trascendental" "contiene en sí misma la responsabilidad en la organización natural de la ciencia, la filosofía pura trascendental y todo el lado de las ciencias naturales e históricas". En cualquier caso, tal cuestión de la injerencia de la filosofía sobre el quehacer científico fue problemática desde el comienzo mismo. A la hora de organizar el trabajo y la institucionalidad, von Humboldt adopta una actitud más equilibrada, enumera cuatro disciplinas fundamentales para ese conocimiento primero o Wissenschaft, sin orden de prioridad: historia, filología, matemáticas, y filosofía a la que agregará además una quinta, la antropología. Porque en la concepción de von Humboldt, explica Piché, "lo que importa no es la jerarquía de los saberes, sino sobre todo la multiplicidad y la riqueza de las ciencias a las cuales el individuo puede escoger consagrarse en vista a su propia formación". En esta concepción más horizontal de distintas disciplinas, que como se sabe luego irían multiplicándose, diversificándose y especializándose crecientemente, se reflejaba, según Piché, la concepción 
de Humbold y Schleiermacher, de que "el proceso de la Bildung debe al término conducir a un hombre mejor, en el sentido en que la práctica de la ciencia es al mismo tiempo una educación moral". En Humboldt hay una mirada de desarrollo integral y menos tendiente a la especialización que en el caso de Fichte; su concepción de Bildung presupone un desarrollo más completo y armónico de distintas facultades y disposiciones, y depende de un ideal de "totalidad" en el desarrollo personal. Un término empleado por Humboldt es Eigentümlichkeit, traducible según Piché como "originalidad" o "particularidad significativa" y "propia" de alguien. Hacer de la propia vida una obra de arte.

Lo anterior conecta con el segundo de los puntos anticipados como fundamentales en el momento de creación de la institución universitaria de las humanidades: ¿cuál es la concepción de sujeto que alimenta la noción de Bildung? Pues, mientras los sujetos son todos iguales ante la ley, no lo son en tanto tales; son anónimos e iguales ante la ley, pero no son "sustituibles" en tanto tales en muchos de los dominios de la vida, he ahí la importancia irrenunciable de la Bildung. Sin embargo, por su propia configuración, el utilitarismo, respetuoso de los fundamentos del liberalismo en términos de filosofía jurídica, es completamente miope ante esta diferencia específica de los sujetos, puesto que solo puede medir resultados, eficiencias, retornos. Todo lo que ve de los individuos está fuera de ellos, como cifra y cuantificación que puede alcanzarse simplemente sustituyendo empleados o consumidores. El "sujeto" es rozado a lo sumo en el marketing, en donde una vez más se lo instrumentaliza en tanto potencial de resultados de venta que incide en los discursos. Naturalmente que esto, que puede ser jurídica y económicamente inobjetable en la mayoría de los casos, es aberrante en cuanto la diferenciación de los individuos. El "individuo moderno culto", en tanto explorador único de sus propias posibilidades vitales, al utilitarismo no le interesa. Los resultados de tan obvio estado de cosas son parejamente evidentes, conocidos por todos, y es prácticamente innecesario mencionarlos. Mientras que para las humanidades en particular el desarrollo en la libertad de los sujetos es valor supremo, para el positivismo y sus derivados más actuales la cuestión de la libertad está encapsulada en un menú previo, existente antes de que, por ejemplo, el estudiante de ciencias se sume al sistema; la elección de objetivos de investigación es opaca y ocurre en instancias superiores -el estudiante elige sus objetivos como parte integrante de estrategias de investigación más amplias ya definidas-y la libertad del nuevo investigador está garantida dentro de márgenes ya definidos. El único formato de conflicto moral conocido es el 
que puede resumirse en los problemas de ética del impacto de la investigación científica en determinadas creencias o prácticas sociales existentes. Pero el problema mayor de la pertinencia misma de la ciencia, la eficacia, la utilidad, en relación con otros valores, queda sin ser planteado o se lo considera algo propio de lunáticos, lo mismo que cualquier forma de conocimiento o práctica que no forme parte de aquello que la ciencia puede manipular o controlar. La tensión entre las humanidades y el desarrollo de la investigación científica básica y aplicada es clara a partir de la conciencia del eje aquí esbozado, que como se ve estuvo muy presente ya en el momento de definir estrategias dentro de la institucionalidad científica moderna.

$* * *$

Muerto el individuo (como agente interpretativo libre) al nacer, se acaban las humanidades como proyecto institucional ligado al "individuo moderno", salvo que se las vea y transforme en espacios en los que compiten, de manera des-individualizada pero intensamente programática, diversas representaciones políticas, sociales, éticas o espirituales sin relación conocida o formulable con sujetos individuales. Es decir, los sujetos se convierten en talking heads que reproducen una u otra de las "líneas de investigación" predefinidas y únicas en todas partes (cuestiones de género, minorías, diversidad, etc.), cuyos contenidos ya existen preformateados antes aun de empezar a "descubrirlos" con la investigación. Tales contenidos no tienen ya ninguna relación conocida con el "proyecto romántico" de las humanidades, es decir, con el proyecto de producirse a sí mismo de forma libre.

Al final de esta historia, está el sujeto, o el ex-sujeto, ahincado hoy ya en las formas inanes de un ultraindividualismo que no es tal, que no puede serlo. Un ultraindividualismo que probablemente a su modo intenta-siquiera psicológicamente-compensar la profunda desindividualización de los contenidos discursivos públicos: lo que se dice en su mayoría en las redes sociales es un re-decir lo ya dicho donde el "individuo" a lo sumo se identifica o espeja en chunks de contenido preformateado. El individuo contemporáneo repite los discursos de autonomía que inventaron sus tatarabuelos en el siglo XIX, pero $¿$ ahora como farsa? El proyecto de individuo moderno, en todo caso, hace mucho que no puede ser, ha muerto con la ida de Rimbaud al África, o aun antes. La originalidad, el genio, la iniciativa única son otros tantos entes en el equipamiento del mundo. Por la razón que decía el mismo Heidegger, ya en 
Ser y Tiempo ("uno huye de la multitud igual que otro huye de la multitud") los espacios de autenticidad, originalidad, etc. son otras tantas formas ya existentes en el impersonal "discurso". Se las podrá acaso experimentar individualmente, pero no se las puede representar salvo como fracciones de alguno de los programas de investigación disponibles. Una concepción de las humanidades que siguiese pues pretendiendo "formar individuos capaces de descubrir o iluminar" cualquier aspecto de la existencia - gente que busque posicionarse a la vanguardia de la especulación y el pensamiento- debería reconocer su propio carácter distópico.

Además, la institución de las humanidades, originalmente creada en torno a la interpretación de textos escritos, ha terminado consolidando las mismas teorías que intensificaron la autodestrucción (o la suave y bien perfumada deconstrucción) de cualquier estrategia de interpretación significativa de textos escritos. Una vez que la estrategia deconstructiva, la teoría crítica y otras "epistemologías de la sospecha" se convirtieron en los únicos modos autorizados de leer, es poco lo que se puede esperar de cualquier lectura. Esta actitud ha cundido y terminado de operar como un agua regia sobre zonas en origen consideradas esenciales dentro del campo humanístico, como la práctica filológica de buscar, transcribir, conservar, comentar e interpretar textos. Durante un persistente tiempo la única actitud suficientemente madura y avisada fue la de no creer en ninguna lectura (siquiera provisoria) de nada. Tal actitud escéptica se dobla además en una actitud meta-discursiva. Es imposible leer, solo se podría, avisadamente, leer cómo leer, postergando el cierre interpretativo hasta el infinito. Según esta tendencia, se llega al absurdo de que un académico de humanidades es el único sujeto absolutamente incapaz de leer, el resto de la gente, felizmente, aún es capaz de leer un texto, entender de él un sentido aproximado y seguir adelante. Tal tendencia, una especie de enfermedad profesional, ha tomado el espacio de la comunicación pública. Las zonas editoriales de los periódicos, por ejemplo, hoy ofrecen mucho menos "línea política" que análisis politológico. Según esa rutina, lo que un político intente decir nunca será escuchado como tal, sino como función diferencial de movimientos internos del "escenario" político. La discusión sobre el Estado, la ciudadanía o el bien común se trocan en análisis ajedrecístico de la comunicación política.

Al final, las prácticas "humanísticas" personales son posibles y remuneradoras en muchos sentidos: escribir, pensar, comentar, narrar la historia, y si no en sentido institucional, al menos en el sentido irreductible de crítica y negatividad pura de un sujeto que se resista. Pero otra cosa es la discusión acerca de la 
institución universitaria de las humanidades, que es la que nos ha ocupado en este trabajo. Su sentido en tanto institución se ha jugado hace tiempo al ingresar en las lógicas de la investigación dirigidas desde el corazón del objetivismo. Las instituciones son más largas y persistentes que las ideas y las tendencias. En la tensión entre prácticas de investigación pre-formateadas e iniciativa individual "libre" (sublimemente moderna) transcurre la agonía de las humanidades, que cada tanto lanza un vislumbre como de claridades viejas, acaso muy significativas, pero seguramente incapaces de convencer o torcer a la maquinaria epistémica y financiera del presente y el futuro visible.

\section{BREVE ANOTACIÓN SOBRE REFERENCIAS}

La mayor parte de las referencias han sido mencionadas, con precisión suficiente, directamente en el texto, y no como aparato de notas al pie, práctica a menudo superflua y que entorpece la lectura en los ensayos humanísticos, además de dar una innecesaria apariencia de cientificidad a lo que se dice. Aquí va alguna ampliación o detalle mayor respecto a las fuentes. Los comentarios iniciales a la discusión sobre el presente de las humanidades en Estados Unidos, así como una serie de citas secundarias, dirigen a una serie de columnas publicadas en su espacio Opinionator por Stanley Fish, en el New York Times, en el año 2008-9, disponibles online en el website del citado periódico. Sobre alguna de ellas se puede escuchar una reacción especialmente interesante en el podcast de entrevista a Richard Rorty en la extraordinaria serie de Robert Harrison, Entitled Opinions About Life and Literature, disponible gratuitamente en iTunes. Un libro valioso donde se puede profundizar la cuestión de las humanidades y las corporaciones es el mencionado Frank Donoghue (2008-04-30). The Last Professors: The Corporate University and the Fate of the Humanities. Oxford University Press. Kindle Edition. Se puede considerar también Roger Kimball. Tenured Radicals: How Politics Has Corrupted Our Higher Education. Fordham University Press, 2008. Este último tiene un exceso de ira en sus visiones políticas, lo que no le impide acertar en varios de los diagnósticos que presenta, y que apoya con muy numerosos datos de primera mano. Sobre la cuestión de los orígenes de la universidad, la lectura de los textos originales es facilitada por la serie dirigida por Ferry, Luc, J-P Person y Alain Renaut: Philosophies de l'Université. L'idealism allemand et la question de l'Université. Payot, París, 1979, que traduce al francés textos de Fichte, Schleiermacher y W. von 
Humboldt sobre este asunto. Hay un artículo que resume estas discusiones, disponible en castellano: Claude Piché, "Fichte, Schleiermacher y W. von Humboldt, sobre la creación de la Universidad de Berlín", Praxis Filosófica, nueva serie, 21, Jul.-Dic. 2005: 129-155. Una interesante conexión, que he referido al comienzo, entre la fundación de la universidad moderna, la cuestión del ocio y el contrato implícito Estado-ciudadano moderno puede leerse en Hans Ulrich Gumbrecht, "The Origins of Literary Studies -And Their End?", Stanford Humanities Review, Vol. 6.1 - 1998. 